\title{
The role of sexual and asexual reproduction in structuring high latitude populations of the reef coral Pocillopora damicornis
}

\author{
KJ Miller ${ }^{1}$ and DJ Ayre ${ }^{1,2}$ \\ Department of Biological Sciences, Institute for Conservation Biology, University of Wollongong, Wollongong NSW 2522, Australia
}

\begin{abstract}
The genotypic composition of populations of the asexually viviparous coral Pocillopora damicornis varies in a manner that challenges classical models of the roles of sexual and asexual reproduction. On the geographically isolated Hawaiian reefs and high latitude reefs in Western Australia, $P$. damicornis populations are highly clonal although it has been argued that sexual reproduction via broadcast spawning generates widely dispersed colonists. In contrast, on eastern Australia's tropical Great Barrier Reef populations show little evidence of clonality. Here, we compare the genotypic diversity of adult and juvenile colonies of $P$. damicornis at seven sites on eastern Australia's high latitude Lord Howe Island reefs to determine if levels of clonality vary with habitat heterogeneity and age of colonies (as predicted by theory) or alternatively if clonality is again always high as for other
\end{abstract}

isolated reef systems. We found $55-100 \%$ of the genotypic diversity expected for random mating at all seven sites and little evidence of asexual recruitment irrespective of habitat heterogeneity (sheltered versus wave exposed) or colony age. We found reduced levels of genetic diversity compared with tropical reefs (2.75 versus 4 alleles/locus), which supports earlier findings that Lord Howe Island is an isolated reef system. Furthermore, heterozygote deficits coupled with significant genetic subdivision among sites $\left(F_{S T}=0.102 \pm 0.03\right)$ is typical of populations that have limited larval connections and are inbred. We conclude that the genetic structure of $P$. damicornis at Lord Howe Island reflects populations that are maintained through localised recruitment of sexually produced larvae.

Heredity (2004) 92, 557-568, advance online publication, 21 April 2004; doi:10.1038/sj.hdy.6800459

Keywords: range limits; genotypic diversity; habitat diversity; recruitment; self-seeding; hybridisation

\section{Introduction}

Theory predicts that in stable habitats, populations of species that reproduce both sexually and asexually should become dominated by a few well-adapted genotypes (Williams, 1975; Maynard-Smith, 1978; Carvalho, 1994). In contrast, where moderate levels of disturbance or environmental variation occur, higher levels of genotypic diversity should be favoured (Williams, 1975; Sebens and Thorne, 1985; Bengtsson and Ceplitis, 2000). Indeed, these simple predictions seem well supported by studies both in terrestrial and aquatic ecosystems. For example, in freshwater systems cyclical parthenogens such as Daphnia pulex use asexual reproduction for rapid clonal expansion when water bodies first fill and conditions are relatively stable - resulting in predictably low levels of genotypic diversity. However, later in the season as ponds dry or freeze and population densities escalate, sexual reproduction is used to produce genotypically diverse offspring that will act as colonists of other habitats (Hebert et al, 1988). Similar patterns are observed in other cyclical parthenogens such as aphids

Correspondence: K Miller, School of Zoology, University of Tasmania, Private Bag 5, Hobart, Tasmania 7001, Australia.

E-mail: karen.miller@utas.edu.au

${ }^{2}$ Joint senior authors.

Received 29 September 2003; accepted 24 February 2004; published online 21 April 2004
(Simon et al, 2002) and rotifers (Carmona et al, 1993) although in ecosystems that are less subject to strong seasonal fluctuations, associations between habitat and genotypic diversity are also evident. For example, the levels of sexual and asexual reproduction in plants may vary with biotic and abiotic factors including latitude (Dorken and Eckert, 2001) and population density (van Kleunen et al, 2001). In marine environments, populations of sea anemones on relatively homogeneous, stable platforms or rock walls may be highly clonal (Hoffmann, 1986; Ayre et al, 1991) and dominated by locally adapted clones (Ayre, 1995). On less stable and more heterogeneous boulder shores, sexual recruits are more successful and subsequently levels of genotypic diversity are higher and match expectations for random mating (Ayre, 1984).

Pocillopora damicornis, one of the most well studied and widely distributed reef corals, may well be expected to display a population structure typical of organisms with a mixed mode of reproduction. It can reproduce asexually via fragmentation (Highsmith, 1982) but is also asexually viviparous, brooding asexually generated planulae within the polyp (Stoddart, 1983; Ayre and Miller, in press). The brooded planulae are released in lunar cycles, with peak planula production occurring during summer months (Richmond and Jokiel, 1984; Tanner, 1996). In addition to asexual reproduction, $P$. damicornis is thought to reproduce sexually through broadcast spawning. The hermaphroditic polyps undergo an annual gametogenic cycle (Harriott, 1983; Stoddart 
and Black, 1985; Glynn et al, 1991; Ward, 1992; Diah Permata et al, 2000), although spawning in P. damicornis has never been observed - only inferred from the disappearance of mature gametes in histological samples (Stoddart and Black, 1985; Ward, 1992).

The dispersal potential of $P$. damicornis larvae also fits the expectation that asexual reproduction is used to maintain populations of locally adapted clones, whereas sexual reproduction is used to generate genetically diverse colonists. The asexual brooded planulae are competent to settle upon release, and generally do so within a few hours (Harrigan, 1972 and pers. obs.). In contrast, sexual larvae produced via broadcast spawning may have as much as a 4-6-day planktonic developmental period, and consequently dispersal potential may be high (Harrison and Wallace, 1990). Indeed, for the high latitude populations at Rottnest Island in Western Australia (Stoddart, 1984a,b) and Hawaii (Stoddart, 1986), the overall genetic structure of $P$. damicornis indicates that local populations are dominated by a small number of clones and Stoddart (1984a,b) argues that sexual reproduction may have been used to generate colonists.

In contrast, however, populations of $P$. damicornis on Australia's Great Barrier Reef (GBR) show no evidence of asexual recruitment and genetic variation matches expectations of random mating (Benzie et al, 1995; Ayre et al, 1997). This is despite the fact that we have recently shown that the brooded planulae, which are the only documented reproductive output of $P$. damicornis on the GBR, are generated asexually (Ayre and Miller, in press). Thus, although all studies to date indicate that $P$. damicornis always invests heavily in asexual reproduction across its range (individual colonies may brood thousands of planulae each year), the population structures in different regions vary greatly and in a manner that defies simple interpretation and may well be confounded by a number of factors. For example, studies in high latitude areas (which represent the edge of the specie's range) are largely restricted to sheltered embayments, where P. damicornis is the dominant coral species and populations are isolated from external sources of recruitment (eg Stoddart, 1984a, b, 1986). Studies on the GBR have focussed on stressful reef flat and crest habitats (Benzie et al, 1995; Ayre et al, 1997; Ayre and Miller, in press), which have high species diversity and are exposed to oceanic influences (eg Connell, 1978; Done, 1982). Thus, the contrasting population structures could reflect the greater spatial and temporal variability of tropical coral reefs versus the relative stability of high latitude reefs.

Although it does not explain the lack of clonality detected in surveys of P. damicornis on tropical coral reefs (Benzie et al, 1995; Ayre et al, 1997), an alternate explanation for the apparently contrasting contribution of asexual reproduction to recruitment in $P$. damicornis from Western Australia and the GBR may lie in the effects of geographic isolation and range limits. Extremes of habitat heterogeneity often occur at the end of a species range, where conditions can be stressful and populations isolated. As a consequence of reduced connections and recruitment from outside, peripheral populations are expected to exhibit reduced levels of genetic and genotypic diversity from the combined effects of founder events, drift, inbreeding and site-specific selection. Certainly, reduction of genetic diversity has been demonstrated for a variety of terrestrial and marine species at the edge of their range (eg Lesica and Allendorf, 1995; Frankham, 1996; GarciaRamos and Kirkpatrick, 1997; Lammi et al, 1999) and this is generally perceived as a threatening process. However, it is also true that many organisms at the edge of their range or in ecologically marginal habitats exhibit reproductive tactics that actively reduce genotypic diversity, for example there is an increased prevalence of asexual reproduction in the intertidal (Hughes, 1989; Carvalho, 1994). Indeed, some organisms with complex life histories may be expected to shift both to self-seeded recruitment and a greater reliance on asexual reproduction in marginal or stressful environments. Ultimately, this may exacerbate the low levels of genetic and genotypic diversity that are predicted to occur in peripheral populations.

Ayre and Hughes (2004) have demonstrated that reef crest populations of $P$. damicornis and four other coral species from the high latitude reefs at Lord Howe Island off the east coast of Australia show lower levels of genetic diversity relative to populations on the GBR. However, they detected little evidence of clonal replication in populations of adults suggesting generalities about the prominence of asexual reproduction at the end of its range may not apply to $P$. damicornis. Alternately, as previous studies have focussed only on adult colonies, the importance of asexual recruitment may be masked if, for instance, postsettlement processes prevent the dominance of a few genotypes within a location even when asexual recruitment is high (eg Ayre and Miller, in press). Unfortunately, the nature of sampling in their earlier study prohibits a more thorough exploration of the relative importance of asexual reproduction in the context of the range limits of $P$. damicornis or the importance of habitat heterogeneity for reproductive mode.

In this study we compare the genetic structure of $P$. damicornis populations from two starkly contrasting habitats at Lord Howe Island to test the prediction that asexual reproduction should be more important in stable than in disturbed habitats, but also to explore the idea that asexual reproduction should proliferate in isolated populations at the end of a species range. Specifically, we have used allozyme electrophoresis to assess the levels of allelic and genotypic diversity among both juveniles and adults from protected and exposed habitats, and to gauge the level of connectivity among populations of $P$. damicornis around Lord Howe Island. Additionally, in the protected lagoon we have systematically sampled large monospecific stands of $P$. damicornis to assess the extent of clonal proliferation and to better understand the importance of asexual reproduction in this species.

\section{Methods}

\section{Study site, study species and sample collections}

Lord Howe Island is an isolated high latitude reef representing the southern limit of reef-building coral distribution on the East Coast of Australia. It is located over $600 \mathrm{~km}$ from the mainland coast and is approximately $200 \mathrm{~km}$ south of the nearest oceanic reefs, Elizabeth and Middleton. P. damicornis is one of the most 
abundant and widespread corals at Lord Howe Island (Harriott et al, 1995) and is found around the island in all reefal habitats, including shallow reef flats, exposed reef edges and protected lagoonal areas. Notably, P. damicornis has two distinct colony growth forms at Lord Howe. On windward and fringing reef areas it displays a morphology that is typical of this species from tropical and subtropical reef areas (eg Veron, 2000) with colonies having short, compact branches and only reaching maximum diameters around $30 \mathrm{~cm}$. However in the sandy lagoon, $P$. damicornis forms large, multilobed mounds, which reach many metres in diameter and can form large mono-specific stands. This lagoonal colony morphology is similar to $P$. damicornis from other high latitude reef areas, such as sheltered areas around Rottnest Island on the West Coast of Australia (D Ayre, pers. obs.). The branches of lagoonal colonies are long (upwards of $30 \mathrm{~cm}$ ) and fragile, and observations of breakages and the extent of the large stands of this species in the lagoon suggest that fragmentation may well be an important life-history strategy in the lagoonal environment. Nonetheless, lobes of these large mounds often differ in colour or branch morphology and hence what is perceived as a single colony may actually include multiple genotypes.

We collected $P$. damicornis tissue samples from seven sites around Lord Howe Island (Figure 1), encompassing two wave-exposure regimes. Three sites were within the protected lagoon and separated by 1-2 km (Comet's Hole, Sylph's Hole and North Bay). The remaining four sites were from exposed locations - one site was immediately south of the edge of the lagoon (Little Island), two sites were located on the eastern side of the island (Ned's Beach and Boat Harbour) and one site was on the northern side of the island (Old Gulch).

In order to determine genetic diversity and assess the contribution of asexual reproduction (via brooded larvae) at each site, we sampled up to 30 'adult' colonies (ie diameter $>15 \mathrm{~cm}$ ) within as small an area as possible (approximately $6 \mathrm{~m} \times 6 \mathrm{~m}$ ) and all 'juvenile' colonies $(<7 \mathrm{~cm}$ diameter) from within the same area. Importantly, we only collected from adult colonies that did not share living or dead skeletal tissue to avoid collecting clone-mates that may have arisen via fragmentation.

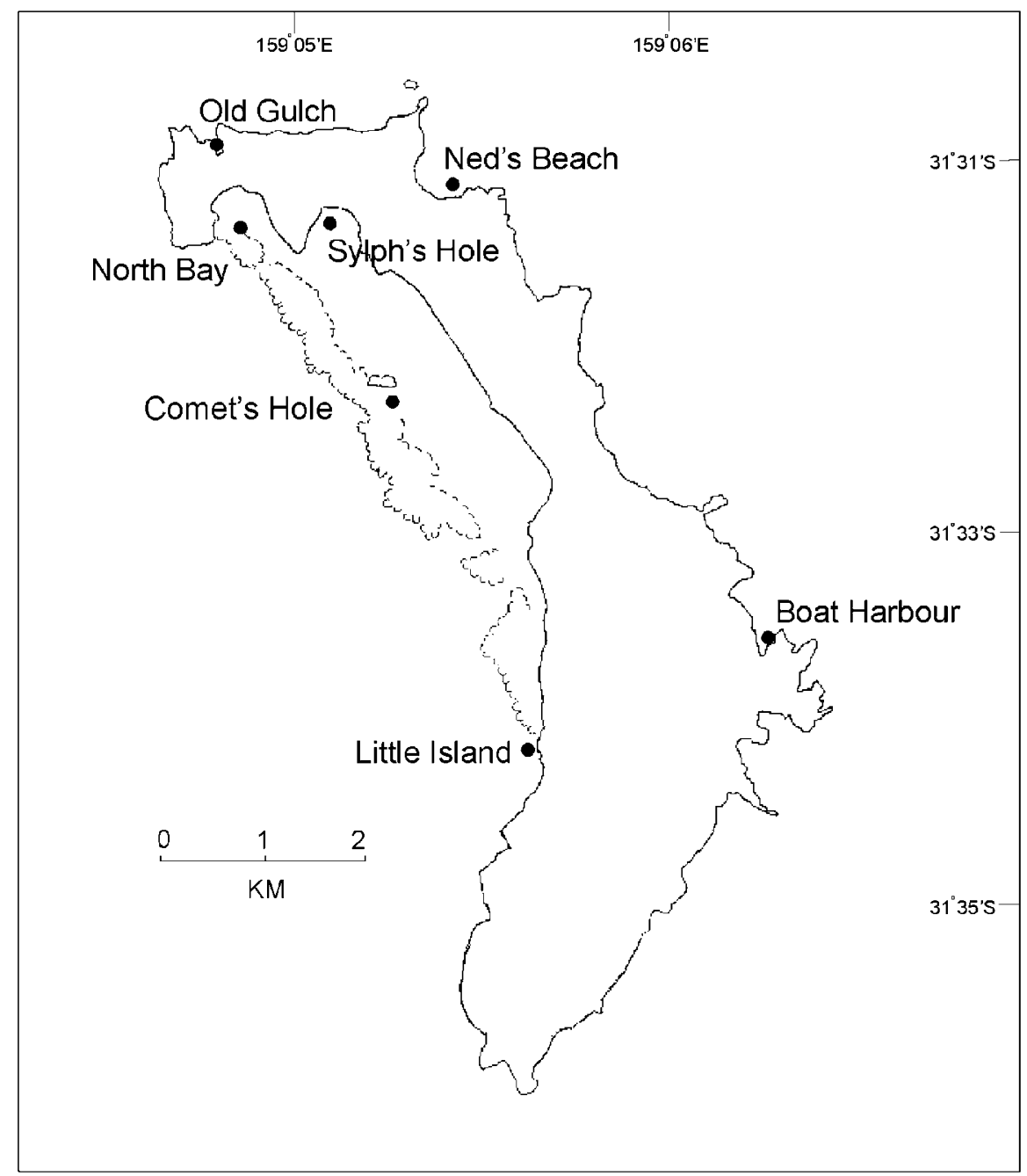

Figure 1 Map of Lord Howe Island showing the approximate location of each of the seven study sites. Note the three sites - North Bay, Sylph's Hole and Comet's Hole are located within the protected lagoon; the remaining four sites are on exposed shallow reef slopes. 
Previous studies have also avoided sampling of probable fission clones (Stoddart, 1984a, b; Benzie et al, 1995; Ayre et al, 1997). In the case of juvenile colonies we only collected those that appeared to have recruited from planulae (ie were symmetrical and attached directly to the substrate) and had clearly not originated from fragments.

We could not collect 'juveniles' at the three lagoonal sites, as there were no colonies in our collection areas that were $<7 \mathrm{~cm}$ in diameter. As described above, lagoonal populations are dominated by large monospecific stands of multilobed mounds. However, to assess the contribution of asexual reproduction to the formation of these monospecific stands within the Lord Howe lagoon, we comprehensively sampled five of the large multilobe mounds - two at Sylph's Hole, two at North Bay and one at Comet's Hole - by mapping the approximate size, position, colour and morphology of each lobe and collecting a tissue sample from each lobe for genetic analysis.

All tissue samples were immediately frozen in liquid nitrogen and transported back to the University of Wollongong where they were stored at $-70^{\circ} \mathrm{C}$ prior to analysis.

\section{Allozyme electrophoresis}

We determined the genotypes of all P. damicornis colonies using allozyme electrophoresis. Tissue samples were ground in an extractant solution ( $10 \mathrm{~g}$ sucrose, $0.1 \mathrm{~g}$ bromophenol blue, $0.1 \mathrm{ml} \beta$-mercaptoethanol to $100 \mathrm{ml}$ Tris $\mathrm{HCl}$ ) prior to loading on $11 \% \mathrm{w} / \mathrm{v}$ starch gels. We stained gels for six enzymes and scored eight loci: glucosephosphate isomerase (Gpi E.C. 5.3.1.9), malate dehydrogenase $\left(M d h^{1 \& 2}\right.$ E.C. 1.1.1.37), mannose phosphate isomerase (Mpi E.C. 5.3.1.8), phosphoglucomutase $\left(\mathrm{Pgm}^{1 \& 2}\right.$ E.C. 2.7.5.1) (assayed using TC8 - buffer no. 5 of Selander et al, 1971) and hexokinase (Hk $k^{1 \& 2}$ E.C. 2.7.1.1) (assayed using TEB - buffer no. 6 of Selander et al, 1971). Alleles at each locus were labelled alphabetically based on decreasing mobility from the origin. We also stained the TEB gels for leucyl tyrosine peptidase $\left(L t p^{1,2}\right.$ and ${ }^{3}$ E.C. 3.4.11) and while there was clear variation with as many as four alleles at the $L t p^{2}$ locus, it was not consistently scorable among our samples so was not used for population-level analyses. However, this locus was diagnostic for the two species $P$. damicornis and Stylophora pistillata (see below).

\section{Data analysis}

We used five approaches to assess the importance of sexual and asexual reproduction to the population structure at each site and to determine if this varied either according to exposure, or between adult and juvenile populations. Firstly, we used $\chi^{2}$ tests to determine if the number of observed and expected heterozygotes were significantly different from the predictions of Hardy-Weinberg equilibrium for randomly mating populations. Wrights Fixation Index $(f)$ was then used to determine the nature of departures from Hardy-Weinberg equilibrium, whereby positive values of $f$ represent heterozygote deficits and negative values represent heterozygote excesses. Heterozygote deficits are a predictable result of inbreeding or selffertilisation whereas asexual reproduction should produce some cases of both heterozygote excesses and deficits (Willis and Ayre, 1985).

Secondly, we determined the number of unique genotypes at each site $\left(N_{\mathrm{g}}\right)$ and compared this to the total number of individuals sampled (ie $N_{\mathrm{g}}: N$ ). As we sampled only a tiny portion of the genome, colonies with identical multilocus genotypes may still be nonclonemates. The ratio $N_{\mathrm{g}}: N$ therefore represents a maximal estimate of the contribution of asexual reproduction to localised recruitment. We then calculated the ratio of observed 8-locus genotypic diversity $\left(G_{0}\right)$ to that expected under conditions of random mating and free recombination $\left(G_{\mathrm{e}}\right)$ (Stoddart and Taylor, 1988). Departures of $G_{\mathrm{o}}: G_{\mathrm{e}}$ from unity were assessed using $t$-tests (Stoddart and Taylor, 1988). Significant values should reflect the combined effects of departures from singlelocus Hardy-Weinberg equilibria and multilocus linkage disequilibria. Such departures are a predictable consequence of asexual reproduction (but may also result from other factors such as population subdivision; Ayre and Hughes, 2000).

In cases where multiple colonies shared the same genotype we calculated the probability that this level of replication might occur via random mating as $P_{r}={ }^{n-1} C_{r-1} p^{(r-1)} q^{(n-r)}$, where $n$ is the number of individual colonies in the sample, $r$ the number of replicates of the 8-locus genotype, $p$ the probability of occurrence of a single copy of the genotype under random mating and $q=1-p$ (Willis and Ayre, 1985). In all cases we adjusted $\alpha$-levels to compensate for large numbers of tests via a sequential Bonferroni procedure. Finally, we determined the genotypes of five to 20 lobes of each of the five multilobed mounds sampled in the Lord Howe lagoon to test the hypothesis that these structures represent single clones.

Genetic variation among sites was assessed using $F$ statistics, calculated as Weir and Cockerhams' $\theta$, using the software package TFPGA (Miller, 2000). For these analyses, adult and juvenile colonies were pooled at each site, but we also calculated $\theta$ among the adult populations and among populations of juveniles to assess if the level of subdivision varied among age classes. Mean $\theta$ $( \pm S E)$ in all cases was calculated by jacknifing over loci. Departures from panmixis among sites (ie $\theta=0$ ) were tested using the $95 \%$ confidence intervals of $\theta$, calculated by bootstrapping over loci. Hierarchical F-statistic analysis was used to partition genetic variance (a) among sites within exposure $\left(F_{S E}\right)$ and $(b)$ between protected and exposed sites $\left(F_{E T}\right)$. UPGMA cluster analysis based on Nei's unbiased genetic distance $(D)$ was used to assess the genetic similarity among the seven sites as well as to compare genetic similarity between adults and juveniles at each of the four exposed sites.

In screening the genotypes of the P. damicornis colonies collected at Lord Howe Island, we discovered 24 individuals that had unusual genotypes, and in most instances these were juvenile colonies that were $<2 \mathrm{~cm}$ in diameter. Comparisons with genotypes of the sympatric pocilloporiid $S$. pistillata (collected during an earlier study, see Ayre and Hughes, 2004) indicated that these small colonies had been misidentified and were in fact $S$. pistillata rather than $P$. damicornis. This finding highlights the difficulty in accurately identifying very small pocilloporiid colonies, and subsequently these misidentified colonies were excluded from the analyses. 
However, we did include the S. pistillata colonies with the $P$. damicornis data in a principal coordinate analysis to examine the entire data set for the presence of genetic groups that might relate either to the presence of multiple species or hybrids within the collection and the presence of genetic groups associated with exposure.

\section{Results}

\section{Population structure}

Overall, the genetic structure of the seven local populations of P. damicornis was consistent with expectations for predominantly sexual rather than asexual recruitment, and did not differ between adult and juvenile samples. However, our data imply that there was a slightly greater level of asexual recruitment at exposed rather than sheltered sites.

The levels of single-locus heterozygosity rarely matched expectations for Hardy-Weinberg equilibria but heterozygous deficiencies were most common, as expected for inbreeding or self-fertilisation. Of 56 singlelocus tests across eight loci, we found 38 cases of heterozygote deficiency and 18 excesses (Table 1). However, only two of these remained significant after Bonferroni correction of $\alpha$-levels, and these were both heterozygote deficits (at the Hk-1 locus for Little Island adults and Pgm-1 locus at North Bay, Table 1)

The levels of 8-locus genotypic diversity were also usually consistent with a high degree of sexual recruitment, as judged by both the numbers and diversity of genotypes detected and the levels of replication of individual genotypes. Values of $N_{g}: N$ at each site were moderate to high, ranging from 0.55 to 0.86 (Table 2), and there was little difference in the ratio $N_{\mathrm{g}}: N$ between the adults and juveniles at any site. Exposed sites were slightly, but not significantly, less diverse than sheltered sites $\left(0.65 \pm 0.05\right.$ cf $\left.0.81 \pm 0.03, t_{5}=2.42, P=0.06\right)$. Similarly, the ratio of observed to expected genotypic diversity $\left(G_{\mathrm{o}}: G_{\mathrm{e}}\right)$ for pooled samples of adults and juveniles was always relatively high (0.55-0.91) with juveniles more diverse than adults in three of four sites. However, $G_{\mathrm{o}}: G_{\mathrm{e}}$ for pooled sets of adults and juveniles was, on average, significantly lower at the exposed sites than the protected sites $(0.63 \pm 0.04$ of $0.85 \pm 0.05$, $t_{5}=3.36 \pm 0.02, P=0.02$, Table 2).

Table 1 Wright's fixation index ( $f$ ) for Pocillopora damicornis from seven sites at Lord Howe Island

\begin{tabular}{|c|c|c|c|c|c|c|c|c|c|c|c|}
\hline \multirow[t]{3}{*}{ Locus } & \multicolumn{3}{|c|}{ Sheltered } & \multicolumn{8}{|c|}{ Exposed } \\
\hline & \multirow{2}{*}{$\frac{\text { Comet's Hole }}{\text { Adult }}$} & \multirow{2}{*}{$\frac{\text { North Bay }}{\text { Adult }}$} & \multirow{2}{*}{$\frac{\text { Sylph's Hole }}{\text { Adult }}$} & \multicolumn{2}{|c|}{ Old Gulch } & \multicolumn{2}{|c|}{ Little Island } & \multicolumn{2}{|c|}{ Ned's Beach } & \multicolumn{2}{|c|}{ Boat Harbour } \\
\hline & & & & Adult & Juvenile & Adult & Juvenile & Adult & Juvenile & Adult & Juvenile \\
\hline Gpi & -0.244 & -0.018 & 0.247 & 0.157 & 0.300 & 0.194 & 0.109 & 0.399 & 0.214 & 0.067 & -0.029 \\
\hline$H k-1$ & 0.142 & 0.449 & 0.340 & -0.256 & -0.340 & $0.751^{* * *}$ & 0.029 & 0.276 & 0.506 & 0.375 & 0.494 \\
\hline$H k-2$ & - & - & - & - & - & - & 1.000 & - & - & 0.653 & -0.017 \\
\hline$M d h-1$ & - & - & - & - & - & -0.017 & - & -0.034 & - & - & - \\
\hline$M d h-2$ & - & - & - & - & 0.409 & - & 0.350 & 0.256 & 1.000 & - & - \\
\hline Mpi & 0.254 & 0.310 & 0.033 & - & - & -0.250 & -0.222 & 0.067 & 0.06 & -0.205 & -0.199 \\
\hline Pgm-1 & 0.107 & $0.432^{*}$ & -0.075 & 0.093 & -0.149 & 0.233 & 0.240 & 0.145 & 0.421 & -0.294 & 0.060 \\
\hline Pgm-2 & 0.175 & -0.074 & 0.628 & - & -0.037 & - & - & -0.091 & - & - & - \\
\hline
\end{tabular}

Significant results from tests for departures from Hardy-Weinberg equilibrium (comparing observed and expected heterozygotes and homozygotes) are indicated by ${ }^{* * *} P<0.001 ;{ }^{*} P<0.05$.

Table 2 Genotypic diversity for Pocillopora damicornis from seven sites around Lord Howe Island

\begin{tabular}{|c|c|c|c|c|c|c|c|c|}
\hline Population & & $N$ & $N_{\mathrm{g}}$ & $N_{\mathrm{g}}: N$ & $G_{\mathrm{o}}$ & $G_{\mathrm{e}}( \pm S E)$ & $G_{\mathrm{o}}: G_{\mathrm{e}}$ & $P$ \\
\hline Comets Hole & Adult & 26 & 20 & 0.77 & 17.8 & $20.1( \pm 3.43)$ & 0.89 & 0.25 \\
\hline North Bay & Adult & 29 & 23 & 0.79 & 16.8 & $22.4( \pm 3.76)$ & 0.75 & 0.07 \\
\hline Sylphs Hole & Adult & 29 & 25 & 0.86 & 22.7 & $24.8( \pm 2.93)$ & 0.91 & 0.24 \\
\hline \multirow{3}{*}{ Old Gulch } & Adult & 26 & 15 & 0.58 & 10.9 & $17.8( \pm 3.52)$ & 0.61 & 0.03 \\
\hline & Juvenile & 14 & 9 & 0.64 & 7.5 & $11.5( \pm 2.46)^{\dagger}$ & 0.65 & 0.07 \\
\hline & Overall & 40 & 22 & 0.55 & 13.6 & $24.9( \pm 4.53)$ & 0.55 & $0.008^{*}$ \\
\hline \multirow[t]{3}{*}{ Little Is } & Adult & 30 & 20 & 0.67 & 16.7 & $26.0( \pm 3.34)$ & 0.64 & $0.005^{*}$ \\
\hline & Juvenile & 30 & 28 & 0.93 & 26.5 & $26.0( \pm 3.34)^{\dagger}$ & 1.02 & 0.55 \\
\hline & Overall & 60 & 47 & 0.78 & 37.5 & $50.1( \pm 5.28)$ & 0.75 & $0.01^{*}$ \\
\hline \multirow[t]{3}{*}{ Ned's Beach } & Adult & 30 & 23 & 0.77 & 17.3 & $26.3( \pm 3.43)$ & 0.66 & $0.007^{*}$ \\
\hline & Juvenile & 11 & 8 & 0.73 & 6.4 & $10.3( \pm 1.54)^{\dagger}$ & 0.62 & $0.01^{*}$ \\
\hline & Overall & 41 & 28 & 0.68 & 19.8 & $32.7( \pm 4.62)$ & 0.61 & $0.004^{*}$ \\
\hline \multirow[t]{3}{*}{ Boat Harbour } & Adult & 30 & 19 & 0.63 & 14.8 & $23.6( \pm 3.72)$ & 0.63 & 0.01 \\
\hline & Juvenile & 30 & 24 & 0.8 & 21.3 & $23.6( \pm 3.72)^{\dagger}$ & 0.9 & 0.27 \\
\hline & Overall & 60 & 35 & 0.58 & 26.5 & $43.4( \pm 5.78)$ & 0.61 & $0.002^{*}$ \\
\hline
\end{tabular}

Calculations of $G_{\mathrm{e}}$ based on adult allele frequencies and juvenile $N$.

${ }^{*} P<0.05$ after Bonferroni adjustment. 
Unsurprisingly, given the levels of overall genotypic diversity within each site, we found no evidence that individual clones were numerically dominant within any site and we detected 164 different 8-locus genotypes in our overall sample of 285 adults and juveniles. As we sampled only a small portion of the genome (ie eight moderately variable loci), we expected that at least some colonies would share identical 8-locus genotypes even if $P$. damicornis only used outcrossed sexual reproduction. We found that 51 8-locus genotypes were shared by multiple colonies, within collections from individual sites. However in 30 cases, genotypes were shared by only two colonies and for 26 of these genotypes this level of replication was likely even through random mating
$(P>0.05)$. Of the 21 groups of $>2$ individuals that shared a genotype, the levels of replication were significantly improbable through random mating $(P<0.05)$ in 17 cases. However, in only three cases was the level of replication judged significantly improbable through sexual reproduction after application of a sequential Bonferroni correction to $\alpha$-levels, that is, genotypes shared by seven, four and four individuals at Old Gulch, Ned's Beach and Little Island respectively.

Contrary to expectations, the large multilobe mounds that dominate the lagoon at Lord Howe Island appear to be the product both of sexual and asexual recruitment. Indeed, each of the five mounds was comprised of a minimum of four genotypes. For example, seven

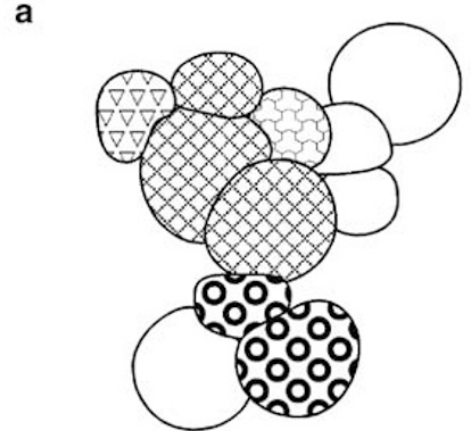

C

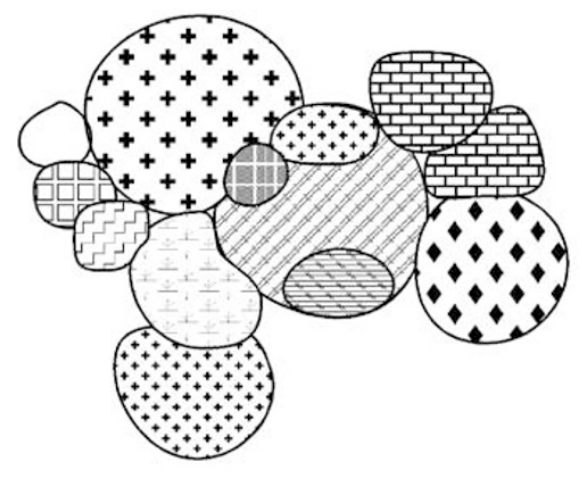

e

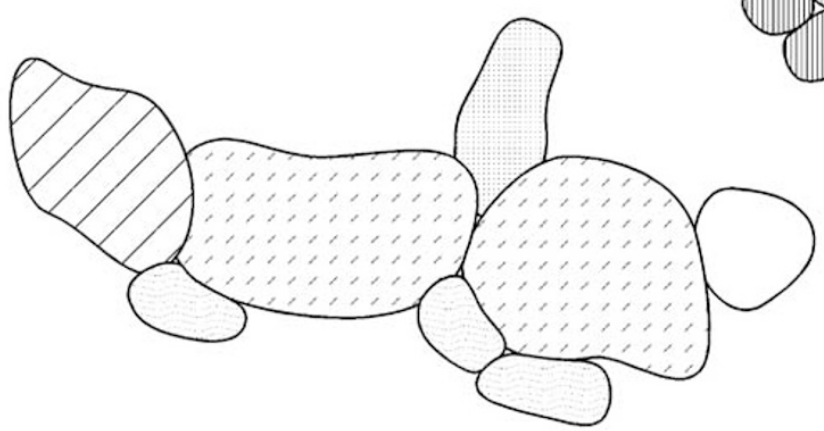

b

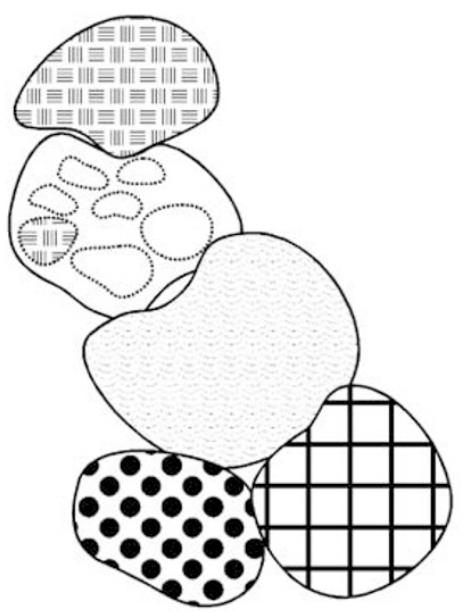

d
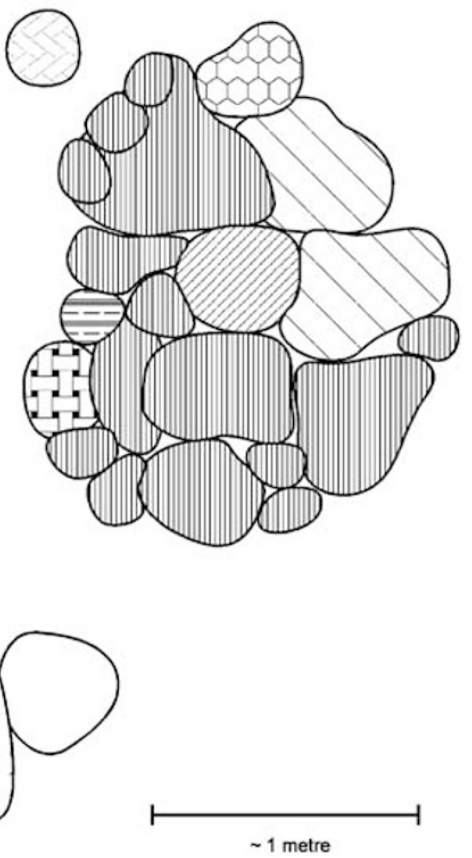

Figure 2 Stylised diagrams of the five multilobed P. damicornis mounds sampled within the lagoon area at Lord Howe Island. (a,c) are from North Bay, (b,e) from Sylph's Hole and (d) from Comet's Hole. Fill patterns correspond to unique genotypes; lobes with identical fill patterns have identical 8-locus genotypes. 
genotypes were present within the 22 lobes we sampled from the Comet's Hole mound and the most common genotype was represented by only 15 lobes (Figure 2d). Additionally, shared genotypes did not correspond with variation in lobe morphology. We recorded colonies with identical genotypes within the same mound that varied either in tissue colour or branch structure. For example, two lobes of North Bay Colony A were yellow rather than brown, but one of the yellow lobes shared its genotype with one of the brown lobes. Similarly, we noted that two lobes of the Comets Hole colony displayed a delicate branching structure in comparison to the rest of the mound, although both of these lobes had unique genotypes.

\section{Allelic diversity and population subdivision}

Overall, we found relatively modest allelic diversity in $P$. damicornis from Lord Howe Island, but high levels of population differentiation that seem related to exposure, but not through any obvious variation in modes of reproduction and recruitment. We recorded an average of $2.75 \pm 0.4$ (SE) alleles per locus at Lord Howe Island compared to $4 \pm 0.7$ (SE) alleles/locus found in comparable samples of $P$. damicornis from the southern GBR (Ayre and Miller, in press).

There were clear patterns in the distribution of alleles among sites, between exposures and between adults and juveniles. For example, all colonies collected at Old
Gulch were homozygous for the $M p i^{(\mathrm{A})}$ allele, whereas $M p i^{(\mathrm{B})}$ was the common allele at most other sites (Table 3). Similarly, the $M p i^{(\mathrm{A})}$ allele was noticeably less abundant in the protected lagoon sites compared with the four exposed sites (Table 3). $M d h-2^{(\mathrm{B})}$ and $P g m-{ }^{(\mathrm{C})}$ alleles were more common in juveniles than in adults and the Pgm$1^{\text {(B) }}$ allele was generally more common in adult colonies than juveniles.

$F_{S T}$ analysis revealed significant genetic subdivision among the seven sites (mean $F_{S T}=0.102 \pm 0.03 \mathrm{SD} ; 95 \% \mathrm{CI}$ 0.05-0.16) (Table 4). Our hierarchical analysis of $F_{S T}$ indicated that the variation in the level of exposure of sites contributed significantly to genetic subdivision $\left(F_{E T}=0.05 \pm 0.013 \mathrm{SD}\right.$, 95\% CI 0.03-0.07). Cluster analysis based on Nei's unbiased genetic distance clearly shows the relationship between exposed and protected sites. The three lagoonal sites (North Bay, Sylph's Hole and Comets Hole) form a discrete cluster, and three of the four exposed sites also cluster together (ie Ned's Beach, Boat Harbour and Little Island - but excluding Old Gulch) (Figure 3). Generally, the protected sites were more similar to each other than the exposed sites, with the average genetic distance among the protected lagoon sites $D=0.007$ (ranging from 0.003 to 0.01 ) and among the exposed sites $D=0.047$ (ranging from 0.009 to 0.085 ). Nevertheless, the level of differentiation between exposed and protected sites was still considerably lower than the level of differentiation among sites within exposures $\left(F_{S E}=0.12 \pm 0.04\right.$ SD, 95\% CI 0.06-0.19).

Table 3 Allele frequencies for Pocillopora damicornis from seven sites around Lord Howe Island, Australia

\begin{tabular}{|c|c|c|c|c|c|c|c|c|c|c|c|c|}
\hline \multicolumn{2}{|c|}{ Locus/allele } & \multirow{2}{*}{$\frac{\text { Comets Hole }}{\text { Adult }}$} & \multirow{2}{*}{$\frac{\text { North Bay }}{\text { Adult }}$} & \multirow{2}{*}{$\frac{\text { Sylphs Hole }}{\text { Adult }}$} & \multicolumn{2}{|c|}{ Old Gulch } & \multicolumn{2}{|c|}{ Little Island } & \multicolumn{2}{|c|}{ Ned's Beach } & \multicolumn{2}{|c|}{ Boat Harbour } \\
\hline & & & & & Adult & Juvenile & Adult & Juvenile & Adult & Juvenile & Adult & Juvenile \\
\hline \multirow[t]{2}{*}{ Gpi } & A & 0.36 & 0.33 & 0.24 & 0.29 & 0.29 & 0.35 & 0.42 & 0.48 & 0.64 & 0.5 & 0.58 \\
\hline & B & 0.64 & 0.67 & 0.76 & 0.71 & 0.71 & 0.65 & 0.58 & 0.52 & 0.36 & 0.5 & 0.42 \\
\hline \multirow[t]{4}{*}{$H k-1$} & A & 0.56 & 0.29 & 0.47 & 0.5 & 0.5 & 0.55 & 0.52 & 0.57 & 0.77 & 0.8 & 0.75 \\
\hline & B & - & 0.02 & 0.09 & 0.06 & 0.04 & 0.05 & 0.02 & 0.03 & 0.05 & - & 0.05 \\
\hline & C & 0.44 & 0.69 & 0.45 & 0.44 & 0.46 & 0.40 & 0.47 & 0.35 & 0.18 & 0.2 & 0.2 \\
\hline & $\mathrm{D}$ & - & - & - & - & - & - & - & 0.05 & - & - & - \\
\hline \multirow[t]{3}{*}{$H k-2$} & A & - & - & - & - & - & - & - & - & - & 0.02 & 0.02 \\
\hline & B & 1 & 1 & 1 & 1 & 1 & 1 & 0.97 & 1 & 1 & 0.95 & 0.98 \\
\hline & $\mathrm{C}$ & - & - & - & - & - & - & 0.03 & - & - & 0.03 & - \\
\hline \multirow[t]{2}{*}{$M d h-1$} & A & 1 & 1 & 1 & 1 & 1 & 0.98 & 1 & 0.97 & 1 & 1 & 1 \\
\hline & B & - & - & - & - & - & 0.02 & - & 0.03 & - & - & - \\
\hline \multirow[t]{2}{*}{$M d h-2$} & A & 1 & 1 & 1 & 1 & 0.85 & 1 & 0.77 & 0.89 & 0.8 & 1 & 1 \\
\hline & B & - & - & - & - & 0.15 & - & 0.23 & 0.11 & 0.2 & - & - \\
\hline \multirow[t]{2}{*}{ Mpi } & A & 0.37 & 0.28 & 0.31 & 1 & 1 & 0.40 & 0.43 & 0.5 & 0.59 & 0.47 & 0.62 \\
\hline & B & 0.63 & 0.72 & 0.69 & - & - & 0.60 & 0.57 & 0.5 & 0.41 & 0.53 & 0.38 \\
\hline \multirow[t]{5}{*}{ Pgm-1 } & A & - & 0.15 & - & - & - & - & - & - & - & 0.12 & 0.15 \\
\hline & B & 0.35 & 0.35 & 0.53 & 0.25 & 0.11 & 0.27 & 0.07 & 0.28 & 0.09 & 0.23 & 0.2 \\
\hline & C & - & 0.02 & 0.02 & 0.35 & 0.61 & 0.17 & 0.41 & - & - & 0.02 & 0.15 \\
\hline & D & 0.56 & 0.43 & 0.45 & 0.29 & - & 0.31 & 0.19 & 0.6 & 0.82 & 0.45 & 0.4 \\
\hline & $\mathrm{E}$ & 0.09 & 0.05 & - & 0.11 & 0.27 & 0.25 & 0.33 & 0.12 & 0.09 & 0.18 & 0.1 \\
\hline \multirow{2}{*}{ Pgm-2 } & A & 0.14 & 0.07 & 0.1 & - & 0.04 & - & - & 0.08 & - & - & - \\
\hline & B & 0.86 & 0.93 & 0.9 & 1 & 0.96 & 1 & 1 & 0.92 & 1 & 1 & 1 \\
\hline \multicolumn{2}{|l|}{ n/locus } & 25.3 & 28.0 & 28.8 & 25.6 & 13.8 & 29.8 & 29.3 & 29.9 & 10 & 29.3 & 28.3 \\
\hline \multicolumn{2}{|l|}{ Ho } & 0.255 & 0.185 & 0.211 & 0.212 & 0.230 & 0.213 & 0.285 & 0.251 & 0.148 & 0.275 & 0.250 \\
\hline \multicolumn{2}{|l|}{$\mathrm{He}$} & 0.282 & 0.264 & 0.263 & 0.214 & 0.234 & 0.285 & 0.330 & 0.318 & 0.258 & 0.268 & 0.271 \\
\hline
\end{tabular}


Table $4 \quad F_{S T}$ values among $P$. damicornis populations at Lord Howe Island (adults and juveniles pooled at each site where applicable)

\begin{tabular}{lc}
\hline Locus & $\theta$ \\
\hline Gpi & 0.043 \\
$H k-1$ & 0.072 \\
$H k-2$ & -0.004 \\
Mdh-1 & 0.005 \\
Mdh-2 & 0.044 \\
Mpi & 0.208 \\
Pgm-1 & 0.103 \\
Pgm-2 & 0.051 \\
Over all loci & 0.101 \\
Mean ( \pm SD) & $0.102(0.03)$ \\
95\% CI & $0.05-0.16$ \\
\hline
\end{tabular}

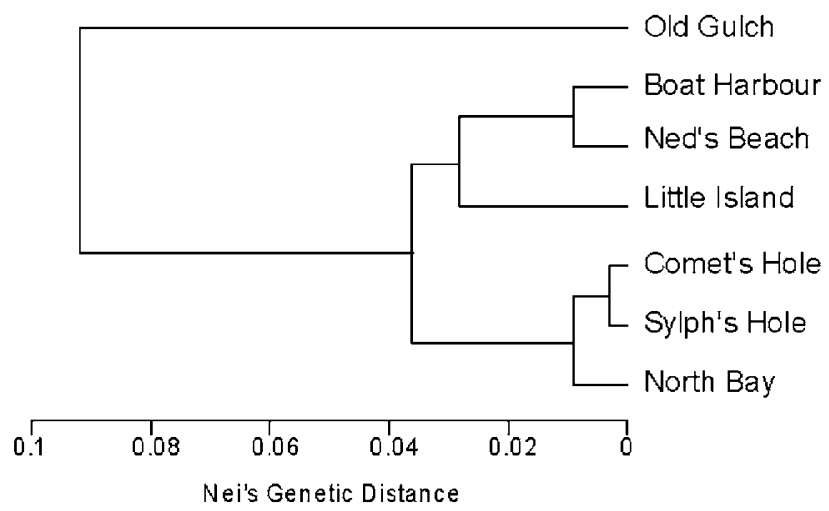

Figure 3 UPGMA cluster analysis based on Nei's Unbiased genetic distance $(D)$ for P. damicornis collected from seven sites around Lord Howe Island (adult and juveniles pooled at each site where applicable).

Further evidence of subdivision among sites is revealed by the cluster analysis that compares adult and juvenile colonies from the four exposed sites (Figure 4). This analysis reveals a strong link between juveniles at each site and the existing adult population, as might be expected if recruitment is local and larval dispersal limited. In addition, similar levels of genetic subdivision were apparent among juvenile populations $\left(F_{S T}=0.12 \pm 0.036 \mathrm{SD}, 95 \% \mathrm{CI} 0.05-0.17\right)$ as among adult populations $\left(F_{S T}=0.08 \pm 0.035 \mathrm{SD}, 95 \%\right.$ CI $\left.0.03-0.15\right)$. This finding adds to our evidence of limited larval dispersal but also suggests that the genetic subdivision observed in adult populations results from larval recruitment, rather than through processes such as fragmentation that might only be apparent in adult populations.

\section{Hybrid genotypes}

Seven of the colonies that we sampled were apparent hybrids between $P$. damicornis and $S$. pistillata. These colonies were, on close examination, intermediate in appearance but easily confused with $P$. damicornis and displayed genotypes intermediate between those of the two species (Figure 5). Their genotypes imply that they were the later generation hybrids or backcrosses as they had (usually homozygous) genotypes of $P$. damicornis at some loci and genotypes of S. pistillata at other loci,

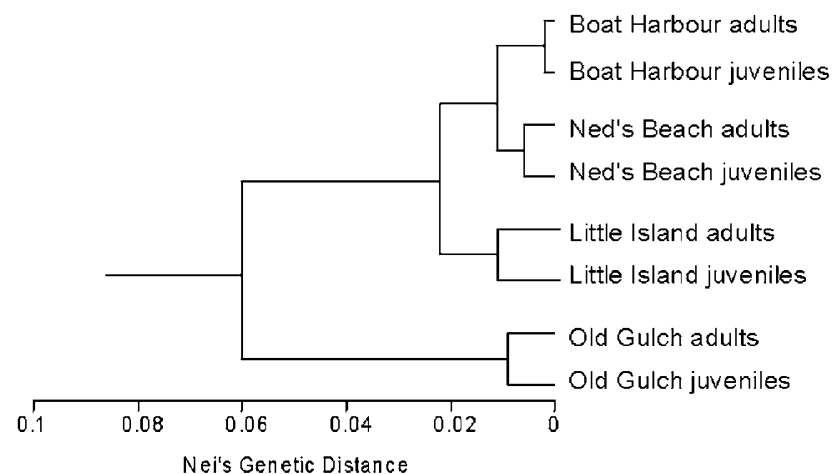

Figure 4 UPGMA cluster analysis based on Nei's unbiased genetic distance $(D)$ for $P$. damicornis adult and juvenile colonies collected from four sites at Lord Howe Island.

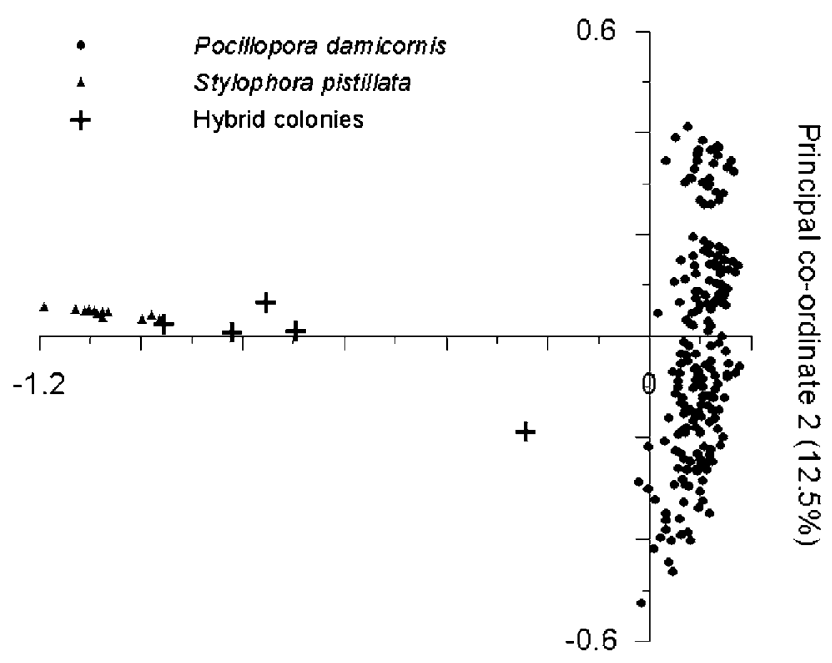

Principal co-ordinate $1(30.2 \%)$

Figure 5 Plot of the first two coordinates from Principal Coordinates Analysis based on 8-locus genotypes of pocilloporid corals collected at Lord Howe Island.

rather than being heterozygous for alleles from both species at all loci. The hybrids were found at three sites (Old Gulch, Sylph's Hole and Ned's Beach), and comprised a mix of adult (3) and juvenile (4) colonies.

\section{Discussion}

Our study of genetic structure in the coral P. damicornis from Lord Howe Island does not support the paradigm that asexual reproduction will be favoured in either geographically isolated or ecologically stable habitats. Since this species has the capacity to generate vast numbers of brooded clonal planulae (Stoddart, 1983; Ayre and Miller, in press) and also has the capacity to reproduce asexually through fragmentation (Highsmith, 1982; Richmond, 1987), we expected that local populations, once founded, would be maintained by localised asexual recruitment. Furthermore we predicted that protected lagoon habitats should be dominated by a few well-adapted genotypes, with higher levels of genotypic diversity in exposed reef areas and also that asexual reproduction would be more important for 
population maintenance at the end of the species range. However, we found little evidence of clonal replication in $P$. damicornis at Lord Howe Island, nor any evidence that asexual reproduction plays any greater role in the maintenance of Lord Howe Island populations, irrespective of exposure, than has been reported elsewhere on the East Coast of Australia (eg Ayre et al, 1997). Indeed, local populations of $P$. damicornis at Lord Howe Island from both exposed reefs and sheltered lagoons appear to be largely derived from sexual recruitment, including some degree of inbreeding or self-fertilisation.

\section{Local population structure}

All of the seven local populations that we sampled were genotypically diverse. Although we detected less genotypic diversity at most sites than expected for outcrossed random mating (ie $G_{0}: G_{e}=1$ ), we attribute this to the combined effects of a low level of clonal replication and some degree of selfing or inbreeding. Our samples were dominated by heterozygous deficiencies and we found in excess of $70 \%$ of the genotypic diversity predicted for randomly mating populations (mean $G_{\mathrm{o}}: G_{\mathrm{e}}=0.72$ ). This result is almost identical to the levels of genotypic diversity reported for populations of $P$. damiconis on the tropical GBR (mean $G_{\mathrm{o}}: G_{\mathrm{e}}=0.77$ at One Tree Island, Ayre and Miller, in press; mean $G_{\mathrm{o}}: G_{\mathrm{e}}=0.88$ across the GBR, Ayre and Hughes, 2000). Moreover, this level of diversity is very similar to that reported for other Australian Pocilloporids that are brooders with internal fertilisation (eg Ayre and Dufty, 1994; Ayre and Hughes, 2000), and is greater than the average for the broadcast spawning South African species $P$. verrucosa (mean $=0.64$, Ridgway et al, 2001). In stark contrast, the highly clonal populations of $P$. damicornis on high latitude reefs in Western Australia and Hawaii display, on average, only $27 \%$ of the diversity expected under random mating (Stoddart, 1984a,b, 1986). Interestingly, the levels of 8-locus genotypic diversity were slightly lower at exposed rather than sheltered sites, and this appeared to reflect a slightly more clonal population structure within these sites including a greater proportion of replicated genotypes and a greater mix of single-locus excesses and deficits.

It is possible that the relatively high levels of genotypic diversity reported for GBR populations of $P$. damicornis (Benzie et al, 1995; Ayre et al, 1997) underestimate the level of localised asexual recruitment to those sites since sampling focussed exclusively upon physically separate adult colonies. However, at Lord Howe Island we found that juveniles at each of the four exposed sites (the only sites with sufficient small colonies) were more genotypically diverse than adults at the same locations. Thus (in contrast to earlier studies), there is little chance that we have missed the evidence of localised asexual recruitment because it has been masked by postsettlement processes.

Most surprisingly, we found that even within the large coral heads in the apparently stable lagoon habitat at Lord Howe, clonal expansion was less important than anticipated. We had predicted that these large contiguous, mono-specific stands would be formed and maintained by clonal replication, but we found numerous instances where morphologically identical and apparently connected lobes were genetically diverse, indicating these heads must be at least partially formed through the settlement of either sexually generated larvae or the asexually generated larvae of multiple clones. Additionally, values of $N_{\mathrm{g}}: N$ and $G_{\mathrm{o}}: G_{\mathrm{e}}$ were, on average, higher at the three lagoon sites than at the four exposed sites. Thus, it appears that asexual reproduction contributes no more to overall population structure in the protected lagoon than on the wave-exposed reefs. Hunter (1993) also found no clear link between wavedisturbance and clonality for the coral Porites compressa in Kaneohe Bay. It would appear that habitat stability as measured by wave exposure is either not an important function affecting reproductive mode in corals, or that other factors such as annual sexual cycles (ie as for cyclical parthenogens) or major disturbance events (ie Ayre and Miller, in press) may be of greater importance in structuring coral communities.

Nonetheless, asexual reproduction undoubtedly plays at least some role in the formation of the large monospecific stands of $P$. damicornis within the lagoon (Figure 2). In clonal populations of $P$. damicornis in Western Australia, the presence of clones across size classes is given as evidence of the recruitment of asexually produced larvae (Stoddart, 1984a, b). Similarly in Hawaii, the geographically wide distribution of clones suggests dispersal and recruitment of asexual planulae (Stoddart, 1988). However, at Lord Howe, the clonal genotypes were generally restricted to a single site, rather than found at multiple sites, and the sparsity of any small colonies (ie $<7 \mathrm{~cm}$ diameter) at the three lagoonal sites suggests larval recruitment (sexual or asexual) is minimal in these areas. Furthermore, we often observed regenerating fragments on the lagoon floor and thus despite the low probability of fragment survival in some habitats (Smith and Hughes, 1999), we suggest that fragmentation will contribute to population maintenance in the protected lagoon at Lord Howe Island. Interestingly, Adjeroud and Tsuchiya (1999) suggested fragmentation is the key form of asexual propagation in $P$. damicornis at the Ryukyu Islands although they relate this to the effects of storm frequency rather than habitat. Nonetheless, what continues to remain unclear, is why $P$. damicornis on the east coast of Australia invests such a large proportion of energy in the brooding of asexual larvae (Ayre and Miller, in press) when there is little evidence that these larvae contribute to population maintenance at any level.

\section{Genetic connections among populations and habitats} The overall population structure of $P$. damicornis at Lord Howe Island reflects sexual reproduction, although we believe that dispersal of sexually generated larvae will be limited. Firstly, our observed low levels of genetic diversity at Lord Howe, relative to tropical reefs, supports results of an earlier study that suggests these reefs are isolated $\left(N_{\mathrm{e}} m \sim 1-2\right.$ between Lord Howe and the GBR; Ayre and Hughes, 2004). Thus, Lord Howe reefs are likely to rely on locally produced larvae for recruitment and, if this is the case, then selection should favour limited dispersal of clonal or sexually produced larvae on isolated reefs. Furthermore, heterozygote deficiencies coupled with subdivision at local scales suggests some degree of inbreeding and/or self-fertilisation. P. damicornis is hermaphroditic and self-fertilising hermaphroditism is considered an important life-history 
strategy for colonists (Baker and Stebbins, 1965; Jackson and Coates, 1986), which may explain the prevalence of brooders on isolated reefs (eg Harriott et al, 1995).

The population structure we have found at Lord Howe Island is very similar to the population structure reported for $P$. damicornis on the GBR (Benzie et al, 1995; Ayre et al, 1997; Ayre and Miller, in press) as well as other brooding corals that do not produce asexual planulae (Ayre and Dufty, 1994; Ayre and Hughes, 2000). Interestingly though, our $F_{S T}$ values among sites at Lord Howe $\left(F_{S T}=0.102 \pm 0.03 \mathrm{SE}\right)$ are more than double the $F_{S T}$ values recorded among $P$. damicornis populations collected on a similar scale (ie $6 \times 6 \mathrm{~m}^{2}$ sites) and separated by similar distances at One Tree Island on the southern GBR $\left(F_{S T}=0.044 \pm 0.025 \mathrm{SE}\right.$, Ayre and Miller, in press). Additionally, our sites at Lord Howe Island show greater genetic subdivision than has been recorded even among $P$. damicornis on reefs along the $>2000 \mathrm{~km}$ length of the GBR $\left(F_{S T}=0.084\right.$, Ayre et al, 1997) or among reefs in the Ryukyu Archipelago $\left(F_{S T}=0.056\right.$, Adjeroud and Tsuchiya, 1999). Such high levels of subdivision among sites at Lord Howe may reflect weaker larval connections even on relatively small scales such as between sites separated by $<1 \mathrm{~km}$, suggesting there may be greater selection for larvae that settle rapidly in isolated environments. Presumably, larvae that are swept away from Lord Howe Island would have little chance of successful settlement given the isolated nature of the reef. The strong genetic similarity between adults and juveniles at each of the four exposed sites (Figure 4) as well as the similar level of genetic subdivision among adult and juvenile populations also support the idea that larvae settle locally. Sitespecific selection may produce similar patterns of genetic relatedness, but is unlikely to explain consistent patterns at multiple loci.

\section{Hybridisation}

One indication that reproductive patterns at Lord Howe Island may be unusual is the presence of hybrids between $P$. damicornis and $S$. pistillata. There is no evidence that hybridisation occurs among pocilloporiid species in tropical reefs and indeed this is the first such suggestion for any brooding coral. Hybridisation has been reported in broadcast-spawning Acroporiids and Faviids on the GBR (Willis et al, 1992; Miller and Babcock, 1997) and in the Caribbean (Szmant et al, 1998; Vollmer and Palumbi, 2002) although fine-scale temporal isolation (Miller and Babcock, 1997) and prezygotic chemical isolating mechanisms such as sperm attractants (Coll et al, 1994) may limit the extent of hybridisation on the reef. Prezygotic isolating mechanisms have not been explored for internally fertilised brooding corals but would seem most likely to fail when mates are scarce and sperm is limiting as might be expected in isolated reef systems at the edge of a species range. Additionally, novel hybrids and allopolyploids are thought to be advantaged in peripheral or ecologically marginal habitats as they are more likely to be successful despite reduced reproductive abilities (Anderson, 1948; Stebbins, 1950, 1959 - see Lesica and Allendorf, 1995). Thus, the persistence of hybrids at Lord Howe Island may further emphasise the isolated nature of these reefs, and highlight their potential vulnerability. In addition, because our sam- pling was directed at $P$. damicornis 'like' colonies we predict that we may well have underestimated the relative abundance of these hybrids at Lord Howe.

\section{Conclusions}

We have demonstrated that the populations of $P$. damicornis at Lord Howe Island, like populations on the tropical GBR, appear to be maintained through sexual reproduction, and that asexual reproduction, either through the generation of brooded planulae or fragmentation, contributes little to overall population structure. We also found no support for the notion that asexual reproduction will be favoured in protected rather than exposed locations and that genotypic diversity will vary predictably with disturbance. Our results have highlighted the relative isolation of the reef communities at Lord Howe, and emphasise the importance of local larval settlement for population persistence. Furthermore, evidence of limited larval dispersal even among sites fringing Lord Howe Island and separated by as little as $1 \mathrm{~km}$ implies that populations will be relatively vulnerable to disturbance. Thus, like other peripheral populations, we suggest that ecological and evolutionary processes such as larval dispersal and selection will be acting differently at Lord Howe than in tropical reef areas emphasising there relative isolation and highlighting the conservation significance of these reefs (eg Lesica and Allendorf, 1995). Experimental evidence is now needed to determine the actual scale of larval dispersal, the degree of adaptation and potential for hybridisation in P. damicornis at Lord Howe Island.

\section{Acknowledgements}

This study was funded by the Australian Research Council through an ARC Large Grant to DJA/KJM and a postdoctoral fellowship to KJM. We thank Craig Sherman and Tanya Llorens for assistance with field collections.

\section{References}

Adjeroud M, Tsuchiya M (1999). Genetic variation and clonal structure in the scleractinian coral Pocillopora damicornis in the Ryukyu Archipelago, southern Japan. Mar Biol 134: 753760.

Ayre DJ (1984). Effects of environment and population density on the sea anemone Actinia tenebrosa. Aust J Mar Freshwater Res 35: 735-746.

Ayre DJ (1995). Localised adaptation of sea anemone clones: evidence from transplantation over two spatial scales. J Anim Ecol 64: 186-196.

Ayre DJ, Dufty S (1994). Evidence of restricted gene flow in the viviparous coral Seriatopora hystrix on Australia's Great Barrier Reef. Evolution 48: 1183-1201.

Ayre DJ, Hughes TP (2000). Genotypic diversity and gene flow in brooding and spawning corals along the Great Barrier Reef, Australia. Evolution 54: 1590-1605.

Ayre DJ, Hughes TP (2004). Climate change, genotypic diversity and gene flow in reef-building corals. Ecology Letters 7: 273-278.

Ayre DJ, Hughes TP, Standish RJ (1997). Genetic differentiation, reproductive mode, and gene flow in the brooding coral Pocillopora damicornis along the Great Barrier Reef, Australia. Mar Ecol Prog Ser 159: 175-187. 
Ayre DJ, Miller KJ (in press). Where do clonal larvae go? Adult genotypic diversity conflicts with reproductive effort in the brooding coral. Pocillopora damicornis. Mar Ecol Prog Ser.

Ayre DJ, Read J, Wishart J (1991). Genetic subdivision within the eastern Australian population of the sea anemone Actinia tenebrosa. Mar Biol 109: 379-390.

Baker HD, Stebbins GL (1965). The genetics of colonizing species. Acadamic Press: New York.

Bengtsson BO, Ceplitis A (2000). The balance between sexual and asexual reproduction in plants living in variable environments. J Evol Biol 13: 415-422.

Benzie JAH, Haskell A, Lehman H (1995). Variation in the genetic composition of coral Pocillopora damicornis and Acropora palifera populations from different reef habitats. Mar Biol 121: 731-739.

Carmona MJ, Serra M, Miracle MR (1993). Relationships between mixes in Brachionus plicatus and preconditioning of the culture medium by crowding. Hydrobiologia 255/256: 145152.

Carvalho GR (1994). Evolutionary genetics of aquatic clonal invertebrates: concepts, problems and prospects. In: Beaumont AR (ed) Genetics and Evolution of Aquatic Organisms. Chapman \& Hall: London.

Coll JC, Bowden BF, Meehan GV, Konig GM, Carroll AR, Tapiolas DM et al (1994). Chemical aspects of mass spawning in corals. 1. Sperm attractant molecules in the eggs of the scleractinian coral Montipora digitata. Mar Biol 118: 177-182.

Connell JH (1978). Diversity in tropical rain forests and coral reefs. Science 199: 1302-1310.

Diah Permata W, Kinzie RA, Hidaka M (2000). Histological studies on the origin of planulae of the coral Pocillopora damicornis. Mar Ecol Prog Ser 200: 191-200.

Done TJ (1982). Patterns in the distribution of coral communities across the central Great Barrier Reef. Coral Reefs 1: 95-107.

Dorken ME, Eckert CG (2001). Severly reduced sexual reproduction in northern populations of a clonal plant, Decodon verticillatus (Lythraceae). J Ecol 89: 339-350.

Frankham R (1996). Relationship of genetic variation to population size in wildlife. Conservation Biol 10: 1500-1508.

Garcia-Ramos G, Kirkpatrick M (1997). Genetic models of adaptation and gene flow in peripheral populations. Evolution 51: 21-28.

Glynn PW, Gassman NJ, Eakin CM, Cortes J, Smith DB, Guzman HM (1991). Reef coral reproduction in the eastern Pacific: Costa Rica, Panama, and Galapagos Islands (Ecuador). Mar Biol 109: 355-368.

Harrigan JF (1972). The planula larva of Pocillopora damicornis: lunar periodicity of spawning and substratum selection behaviour. Thesis. University of Hawaii, 319pp.

Harriott VJ (1983). Reproductive seasonality, settlement, and post-settlement mortality of Pocillopora damicornis (Linnaeus), at Lizard Island, Great Barrier Reef. Coral Reefs 2: 151-157.

Harriott VJ, Harrison PL, Banks SA (1995). The coral communities of Lord Howe Island. Mar Freshwater Res 46: 457-465.

Harrison PL, Wallace CC (1990). Reproduction, dispersal and recruitment of scleractinian corals. In: Dubinsky Z (ed) Coral Reef Ecosystems. Elsevier: Amsterdam, pp 133-207.

Hebert PDN, Ward RD, Weider LJ (1988). Clonal-diversity patterns and breeding-system variation in Daphnia pulex, an asexual-sexual complex. Evolution 42: 147-159.

Highsmith RC (1982). Reproduction by fragmentation in corals. Mar Ecol Prog Ser 7: 207-226.

Hoffmann RJ (1986). Variation in contributions of asexual reproduction to the genetic structure of populaitons of the sea anemone Metridium senile. Evolution 40: 357-365.

Hughes RN (1989). A Functional Biology of Clonal Animals. Chapman \& Hall: London and New York.

Hunter CL (1993). Genotypic variation and clonal structure in coral populations with different disturbance histories. Evolution 47: 1213-1216.
Jackson JBC, Coates AG (1986). Life cycles and evolution of clonal (modular) animals. Phil Trans Roy Soc London B 313: 722

Lammi A, Siikamaki P, Mustajarvi K (1999). Genetic diversity, population size, and fitness in central and peripheral populations of a rare plant Lychnis viscaria. Conservation Biol 13: $1069-1078$

Lesica P, Allendorf FW (1995). When are peripheral populations valuable for conservation? Conservation Biol 9: 753-760.

Maynard-Smith J (1978). The Evolution of Sex. Cambridge University Press: Cambridge.

Miller KJ, Babcock RC (1997). Conflicting morphological and reproductive species boundaries in the scleractinian coral genus Platygyra. Biol Bull 192: 98-110.

Miller MP (2000). Tools for Population Genetic Analyses (TFPGA) V 1.3. A windows program for the analysis of allozyme and molecular population genetic data.

Richmond RH (1987). Energetic relationships and biogeographical differences among fecundity, growth and reproduction in the reef coral Pocillopora damicornis. Bull Mar Sci 41: 594-604.

Richmond RH, Jokiel PL (1984). Lunar periodicity in larva release in the reef coral Pocillopora damicornis at Enewetak and Hawaii. Bull Mar Sci 34: 280-287.

Ridgway T, Hoegh-Guldberg O, Ayre D (2001). Panmixia in Pocillopora verrucosa from South Africa. Mar Biol 139: 175-181.

Sebens KP, Thorne BL (1985). Coexistence of clones, clonal diversity, and the effects of disturbance. In: Jackson JBC, Buss LW, Cook RE (eds) Population Biology and Evolution of Clonal Organisms. Yale University Press: New Haven and London, pp 357-398.

Selander RK, Smith MH, Yank SY, Johnstone WE, Gentry JB (1971). Biochemical polymorphism and systematics in the genus Peromyscus. I. Variation in the old-field mouse Peromyscus polionotus. Stud Genet 6: 49-90.

Simon JC, Rispe C, Sunnucks P (2002). Ecology and evolution of sex in aphids. TREE 17: 34-39.

Smith LD, Hughes TP (1999). An experimental assessment of survival, re-attachment and fecundity of coral fragments. J Exp Mar Biol Ecol 235: 147-164.

Stoddart JA (1983). Asexual production of planulae in the coral Pocillopora damicornis. Mar Biol 76: 279-284.

Stoddart JA (1984a). Genetic structure within populations of the coral Pocillopora damicornis. Mar Biol 81: 19-30.

Stoddart JA (1984b). Genetic differentiation amongst populations of the coral Pocillopora damicornis off southwestern Australia. Coral Reefs 3: 149-156.

Stoddart JA (1986). Biochemical genetics of Pocillopora damicornis in Kaneohe Bay, Oahu, Hawaii. In: Jokiel PL, Richmond RH, Rogers RA (eds) Coral Reef Population Biology. Technical Report No. 37, Hawaii Institute of Marine Biology. Hawaii Univ., Sea Grant Coll. Program: Honolulu, HI (USA), pp 133-149.

Stoddart JA (1988). Coral populations fringing islands: larval connections. Aust J Mar Freshwater Res 39: 109-115.

Stoddart JA, Black R (1985). Cycles of gametogenesis and planulation in the coral Pocillopora damicornis. Mar Ecol Prog Ser 23: 153-164.

Stoddart JA, Taylor JF (1988). Genotypic diversity: estimation and prediction in samples. Genetics 118: 705-711.

Szmant AM, Weil E, Miller MW, Colon DE (1998). Hybridization within the species complex of the scleractinian coral Montastraea annularis (Ellis and Solander, 1786). Mar Biol 129. 561-572.

Tanner J (1996). Seasonality and lunar periodicity in the reproduction of Pocilloporid corals. Coral Reefs 15: 59-66.

van Kleunen M, Fischer M, Schmid B (2001). Effects of intraspecific competition on size variation and reproductive allocation in a clonal plant. Oikos 94: 5151-5524. 
Veron JEN (2000). Corals of the World. Australian Institute of Marine Science: Townsville.

Vollmer SV, Palumbi SR (2002). Hybridization and the evolution of reef coral diversity. Science 296: 2023-2026.

Ward S (1992). Evidence for broadcast spawning as well as brooding in the scleractinian coral Pocillopora damicornis. Mar Biol 112: 641-646.

Williams GC (1975). Sex and Evolution. Princeton University: Princeton, NJ.
Willis BL, Ayre DJ (1985). Asexual reproduction and genetic determination of growth form in the coral Pavona cactus: biochemical genetic and immunogenic evidence. Oecologia 65: 516-525.

Willis BL, Babcock RC, Harrison PL, Wallace CC (1992). Experimental evidence of hybridisation in reef corals involved in mass spawning events. Proceedings of the Seventh International Coral Reef Symposium. Vol 1, p 504 . 